Article

\title{
Conventional $P-\omega / Q-V$ Droop Control in Highly Resistive Line of Low-Voltage Converter-Based AC Microgrid
}

\author{
Xiaochao Hou ${ }^{1}$, Yao Sun ${ }^{1}$, Wenbin Yuan ${ }^{1}$, Hua Han ${ }^{1, *}$, Chaolu Zhong ${ }^{1}$ and Josep M. Guerrero ${ }^{2}$ \\ 1 School of Information Science and Engineering, Central South University, Changsha 410083, China; \\ houxc10@csu.edu.cn (X.H.); yaosuncsu@gmail.com (Y.S.); ywb_csu@163.com (W.Y.); \\ zclcsu0607@163.com (C.Z.) \\ 2 Department of Energy Technology, Aalborg University, DK-9220 Aalborg East, Denmark; joz@et.aau.dk \\ * Correspondence: hua_han@126.com; Tel.: +86-136-4749-4148
}

Academic Editor: G.J.M. (Gerard) Smit

Received: 2 August 2016; Accepted: 3 November 2016; Published: 11 November 2016

\begin{abstract}
In low-voltage converter-based alternating current (AC) microgrids with resistive distribution lines, the $P-V$ droop with $Q-f$ boost (VPD/FQB) is the most common method for load sharing. However, it cannot achieve the active power sharing proportionally. To overcome this drawback, the conventional $P-\omega / Q-V$ droop control is adopted in the low-voltage AC microgrid. As a result, the active power sharing among the distributed generators (DGs) is easily obtained without communication. More importantly, this study clears up the previous misunderstanding that conventional $P-\omega / Q-V$ droop control is only applicable to microgrids with highly inductive lines, and lays a foundation for the application of conventional droop control under different line impedances. Moreover, in order to guarantee the accurate reactive power sharing, a guide for designing $Q-V$ droop gains is given, and virtual resistance is adopted to shape the desired output impedance. Finally, the effects of power sharing and transient response are verified through simulations and experiments in converter-based AC Microgrid.
\end{abstract}

Keywords: droop control; low-voltage alternating current (AC) microgrid; power sharing; small signal stability

\section{Introduction}

Microgrid is a new concept for integrating renewable distributed resources (DGs) in distribution energy system $[1,2]$. Unlike the conventional power system, microgrid always consists of various renewable DGs, such as, photovoltaic (PV) and wind turbine. These DGs are commonly connected by power electronic converters in parallel. The nature of a converter-based dominated microgrid is different with the grid with synchronous generators (SGs). Compared with the SGs in power plants, converter-based DGs have inherent features: fast response and less-inertia. Thus, in islanded microgrid, converter-based DGs can be treated as controlled voltage sources [3-5].

In the islanded mode, the accurate load demand among multiple DGs is an important task [6]. The control strategies based on communication can achieve excellent voltage regulation and proper power sharing, including concentrated control [7,8], master/slave control [9], and distributed control [10-12]. However, the communication would increase the investment and reduce the system expandability.

To overcome the above disadvantages, the control strategies without communication are preferable. They are generally based on the droop concept [13]. The conventional $P-\omega / Q-V$ droop method is developed by assuming highly inductive equivalent impedance between the DG and the AC bus. However, this assumption is invalid in microgrids where distribution lines are mainly resistive. 
In highly resistive line, the control strategies without communication are generally divided into three categories: the $P-V$ droop with $Q-f$ boost (VPD/FQB) method [14-19], the virtual impedance methods [20-24], and the variants of droop control [25-27]. The detail advantages and disadvantages of these methods [14-27] can be found in our latest review [17].

For low-voltage AC microgrids, the mainly resistive line characteristic is adverse to the conventional droop control [14]. The VPD/FQB offers an alternative method [14-16]. However, the VPD/FQB method cannot properly share load active power, which significantly restricts its applications [17]. To ensure accurate proportional load sharing, a robust droop control is proposed by adding an integral control $[18,19]$. However, the method has a potential issue of requiring the load voltage information which is not local information and is difficult to obtain [17].

Virtual impedance method is a method to change the output impedance characteristic [20-24]. Once the impedance characteristic of a line is shaped from mainly resistive to inductive, the conventional droop could be applied. However, in rural low voltage networks, the values of line resistance are typically large. The larger virtual inductor makes the output voltage drop severely and limits the power output capacity of converters.

There have been some other variants of the droop control for the highly resistive line. A model-free based generalized droop controller (GDC) is developed to remove its dependency to the line parameters on adaptive neuro-fuzzy inference system (ANFIS) [25]. Although the intelligent control structure carefully tracks the GDC dynamic behavior, and exhibits desirable performance for different load change scenarios, the ANFIS controller is slightly complex. In further investigation of the droop concept, power-angle droop control is proposed for rural low voltage networks in [26,27]. The angle droop can improve load power sharing among DGs without a frequency drop. However, if the local control boards are not synchronized with each other, the imperfection of the crystal clock makes frequencies of each DG slightly different, which will lead to system instability [17].

To the best of our knowledge, almost no previous research considers using the conventional droop control in highly resistive line of converter-based AC microgrid. This study proves the validity of conventional droop control in highly resistive line. The feasible condition of stable operation is found through small signal analysis. Moreover, this study provides a potential opinion that the conventional droop control can be extended and applied under arbitrary resistance-inductance (RL) type line impedances. To improve the reactive power sharing, the values of $Q-V$ droop gains are designed. As the line resistances of low voltage AC microgrid are measurable, virtual resistance is also adopted to eliminate the mismatch line resistance. In this paper, the features of studied microgrid are based on as follows: (1) converter-based DGs; (2) multiple parallel-connected DGs; and (3) highly resistive line impedance in low voltage level.

The rest of the paper is organized as follows. In Section 2, the conventional droop control and power transfer principle are briefly introduced. Small signal analyses and the explanation of effectiveness are carried out in Section 3. In Section 4, after analyzing steady state, some measures are taken to improve the proper reactive power sharing. In Section 5, the value of the $Q-V$ droop gain $n$ is designed from the perspective of stability, reactive output capacity, and reactive power sharing. The simulation and experiment results are presented in Sections 6 and 7, respectively. Finally, Section 8 makes the conclusions and gives the future work of this study.

\section{Operation Principle of AC Microgrid}

\subsection{Droop Method in Inductive Microgrids}

To facilitate load sharing and improve reliability in the microgrid with inductive wires, the droop control shown in Equations (1) and (2) is commonly used [13].

$$
\begin{aligned}
& \omega=\omega^{*}-m P \\
& V=V^{*}-n Q
\end{aligned}
$$


where $\omega$ and $V$ are the angular frequency and voltage amplitude reference of a DG, respectively. $\omega^{*}$ and $V^{*}$ represent values of $\omega$ and $V$ at no load, and $m$ and $n$ are droop gains of $P-\omega$ and $Q-V$, respectively.

\subsection{Power Transmission Characteristics in Resistive Microgrids}

In the low voltage microgrid, the distribution line character is mainly resistive $(R>>X)$ as shown in Table 1. In order to explain the matter more easily, this study would neglect the minor line reactance and treat the highly resistive line as pure resistance.

Table 1. Line parameters in microgrid [28,29].

\begin{tabular}{cccc}
\hline Type of Line & Line Resistance $R(\mathbf{\Omega} / \mathbf{k m})$ & Line Reactance $X(\mathbf{\Omega} / \mathbf{k m})$ & Ratio of $\frac{R}{X}$ \\
\hline Low voltage line & 0.642 & 0.083 & 7.7 \\
Medium voltage line & 0.161 & 0.190 & 0.85 \\
High voltage line & 0.06 & 0.191 & 0.31 \\
\hline
\end{tabular}

In the low voltage microgrid with resistive wires, as shown in Figure 1, the power flows obey the following relationship [15].

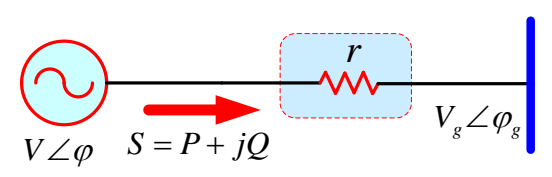

Figure 1. Equivalent circuit of a distributed generator (DG) unit connected to the common bus.

$$
\begin{gathered}
P=\frac{1}{r} V\left(V-V_{g} \cos \delta\right) \\
Q=-\frac{1}{r} V V_{g} \sin \delta \\
\delta=\varphi-\varphi_{g}=\int\left(\omega-\omega_{g}\right) \mathrm{d} t
\end{gathered}
$$

where $V, \varphi, \omega$ and $V_{g}, \varphi_{g}, \omega_{g}$ are voltage amplitude, phase angle and angular frequency of the DG and the common bus, respectively. $r$ represents the line resistance. $\delta$ is the power angle between two voltages.

From Equations (3) and (4), the relationship between active and reactive power is shown in Figure 2. Usually, according to the requirement of normal operation, the power angle $\delta$ should lie in $[-\pi / 2, \pi / 2]$ under the constraints of the stability and transmission efficiency. Given that RL loads are fed, the scope of power angle $\delta$ belongs to $[-\pi / 2,0]$. Furthermore, when resistance-capacitance (RC) loads are fed, $\delta \in[0, \pi / 2]$.

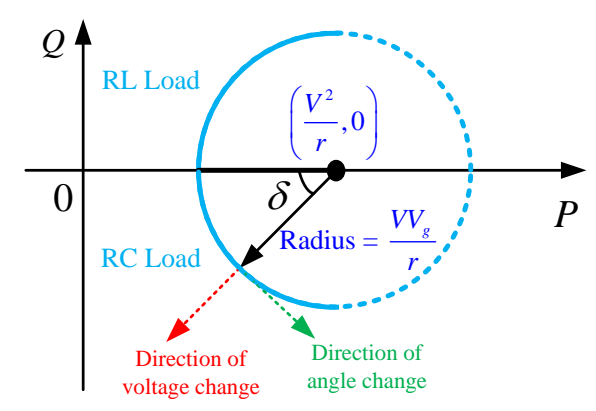

Figure 2. Power circle diagram of Equations (3) and (4). RL: resistance-inductance; and RC: resistance-capacitance. 


\section{Small Signal Analysis}

\subsection{Small Signal Stability}

In this study, we propose to use the droop laws in Equations (1) and (2) to control DGs in the microgrid with resistive wires. To verify its effectiveness, the system stability is investigated in this section.

For simplicity, the small signal stability analysis is carried out $[30,31]$. Assume that $\left(V^{0}, V_{g}^{0}, \delta^{0}\right)$ is the equilibrium point of the system. Linearization of the Equations (1)-(5) in the Laplace domain yields.

$$
\begin{gathered}
\Delta \omega=-m \Delta P \\
\Delta V=-n \Delta Q \\
\Delta P=k_{p \delta} \Delta \delta+k_{p V} \Delta V \\
\Delta Q=k_{q \delta} \Delta \delta+k_{q V} \Delta V \\
s \Delta \delta=\Delta \omega-\Delta \omega_{g}
\end{gathered}
$$

where " $s$ " is the corresponding operator in the Laplace domain, and:

$$
\left\{\begin{array}{l}
k_{p \delta}=\frac{V^{0} V_{g}^{0} \sin \delta^{0}}{r} \\
k_{p V}=\frac{2 V^{0}-V_{g}^{0} \cos \delta^{0}}{r}
\end{array},\left\{\begin{array}{l}
k_{q \delta}=-\frac{V^{0} V_{g}^{0} \cos \delta^{0}}{r} \\
k_{q V}=-\frac{V_{g}^{0} \sin \delta^{0}}{r}
\end{array}\right.\right.
$$

By substituting Equations (6), (7), and (10) into Equations (8) and (9), the characteristic equation of the closed-loop system is obtained.

$$
\left(1+n k_{q V}\right) s+m k_{p \delta}+m n k_{p \delta} k_{q V}-m n k_{p V} k_{q \delta}=0
$$

To determine the system dynamics and stability, the roots of Equation (12) is solved.

$$
s=-\frac{m k_{p \delta}+m n k_{p \delta} k_{q V}-m n k_{p V} k_{q \delta}}{1+n k_{q V}}
$$

For stability, the following conditions should be satisfied.

$$
\left\{\begin{array}{l}
k_{p \delta}+n k_{p \delta} k_{q V}-n k_{p V} k_{q \delta}>0 \\
1+n k_{q V}>0 \\
m>0
\end{array}\right.
$$

According to Equation (11), the simplified stability conditions are obtained from Equation (14):

$$
\begin{cases}n>\frac{-r \sin \delta^{0}}{2 V^{0} \cos \delta^{0}-V_{g}^{0}} ; & \delta^{0} \in[-\pi / 2,0] \\ n<\frac{r}{V_{g}^{0} \sin \delta^{0}} ; & \delta^{0} \in[0, \pi / 2]\end{cases}
$$

In the conventional power system with multi-machines, the power angle is always less than $30^{\circ}$ and too large power angle is easy to cause loss of stability [32,33]. Here, it is assumed that the absolute power angle is less than $30^{\circ}$.

$$
-\frac{\pi}{6}<\delta^{0}<\frac{\pi}{6}
$$

Thus, the droop gain $n$ should be met the following equation.

$$
\frac{r}{2 \sqrt{3} V^{0}-2 V_{g}^{0}}<n<\frac{2 r}{V_{g}^{0}}
$$


Equation (17) reveals that the droop gain $n$ has a large range of values when $\delta^{0} \in[-\pi / 6, \pi / 6]$.

Through the above small signal stability analysis, the stability condition of Equation (17) is given. Moreover, it is worth noting that Equation (13) is effective by omitting the power filters, and thus the order of small signal dynamics is reduced to analyze the damping of the dominant low-frequency mode [30].

\subsection{Explanation of Operating Principle}

To better understand the effectiveness of conventional droop control, this part would give the explanation. According to the small signal analysis of above Section 3.1, the whole small signal model is shown in Figure 3a. In pure resistive line of AC microgrid, Equations (3), (4) and (11) reveal that active power is predominately dependent on the output voltage amplitude, while the reactive power mostly depends on the power angle. Hence, $k_{p \delta}$ and $k_{q V}$ can be approximated to zero. The relationship between $\Delta P-\Delta V$ and $\Delta Q-\Delta \delta$ can be simplify expressed as:

$$
\begin{aligned}
& \Delta P \propto k_{p V} \Delta V \\
& \Delta Q \propto k_{q \delta} \Delta \delta
\end{aligned}
$$

where $\propto$ represents "a positive correlation".

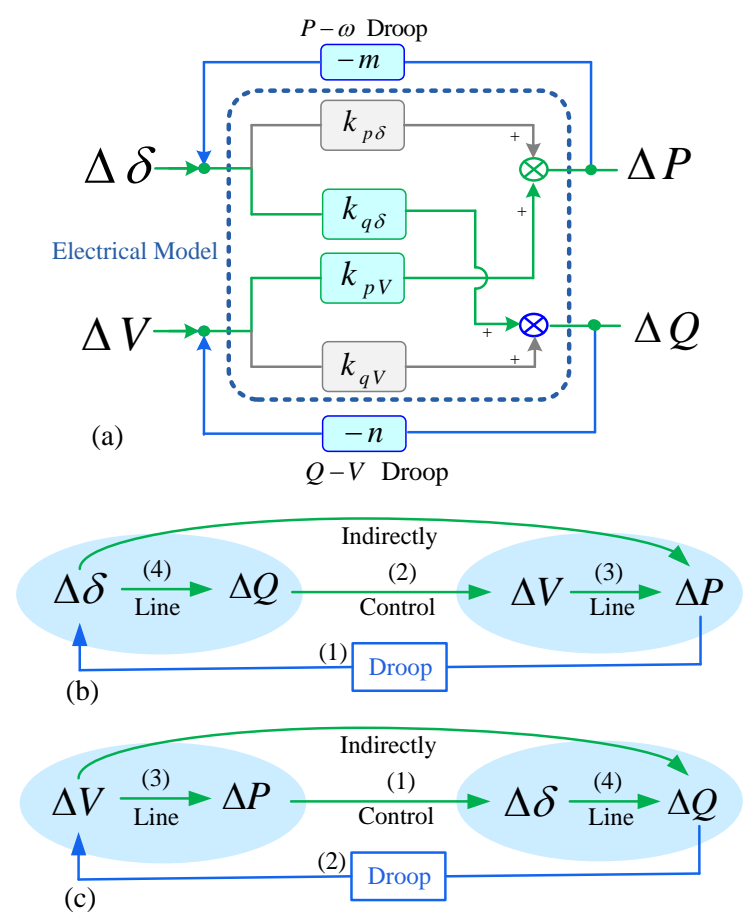

Figure 3. The coupling relationship: (a) the whole small signal model; (b) active power control; and (c) reactive power control.

When the conventional $Q-V$ droop control in Equation (2) is adopted, the negative feedback relation is simplified as:

$$
\Delta V \propto-n \Delta Q
$$

With Equations (18)-(20), the indirect relevance of $P-\delta$ is built as:

$$
\Delta P \propto k_{p V} \Delta V \propto-n k_{p V} \Delta Q \propto-n k_{p V} k_{q \delta} \Delta \delta
$$


Substituting Equation (11) into Equation (21) yields:

$$
\Delta P \propto \frac{n\left(2 V^{0}-V_{g}^{0} \cos \delta^{0}\right) V^{0} V_{g}^{0} \cos \delta^{0}}{r^{2}} \Delta \delta
$$

From Equation (22), the $Q-V$ droop serves as an indirect bridge between active power and power angle. Thus, the power angle can indirectly regulate active power in highly resistive lines of AC microgrid. Moreover, the relevance between active power and power angle could be enhanced by regulating the $Q-V$ droop gain $n$. The indirect coupling relationship is illustrated in Figure 3. Figure $3 b, c$ shows the active power control and reactive power control, respectively.

In Figure 3, with neglecting the voltage dynamics $(n=0)$, the simplified $P-\delta$ dynamic is investigated [30]. Only with regard to active power component can the root in Equation (13) be expressed:

$$
\lambda=-m k_{p \delta}
$$

By considering Equations (4) and (11), $k_{p \delta}$ is negative when the output reactive power is positive. From Equation (23), the system would be unstable. Thus, in pure resistance line, the strong coupling of power components cannot be neglected, and the $Q-V$ droop gain $n$ is vital to guarantee the stable operation in Equation (17).

\section{Steady State Analysis}

When $P$ - $\omega$ droop characteristic is adopted, the active power is ideally shared in the steady-state. This section focuses on discussing the conditions of reactive power sharing. As $\delta$ is normally assumed to be small, Equations (3) and (4) are approximated as [13]:

$$
\begin{gathered}
P \cong \frac{V\left(V-V_{g}\right)}{r} \\
Q \cong-\frac{V V_{g}}{r} \delta
\end{gathered}
$$

And, roughly,

$$
P \cong \frac{V_{g}\left(V-V_{g}\right)}{r}
$$

which represents the delivered active power into the bus.

Power flowing through line resistance yields the associated voltage drop, which is calculated as follows from Equation (26):

$$
V-V_{g}=\frac{r P}{V_{g}}
$$

Substituting Equation (27) into Equation (2) in terms of $V$, the output reactive power of DG is given by:

$$
Q=\frac{V^{*}-V_{g}}{n}-\frac{r P}{n V_{g}}
$$

For a microgrid with two parallel-connected DGs, the error of reactive power sharing is defined as:

$$
\begin{aligned}
\Delta Q & =\frac{Q_{1}}{Q_{1}^{*}}-\frac{Q_{2}}{Q_{2}^{*}} \\
& =\left(V^{*}-V_{g}\right)\left(\frac{1}{n_{1} Q_{1}^{*}}-\frac{1}{n_{2} Q_{2}^{*}}\right)-\frac{r_{1} P_{1}}{n_{1} V_{g} Q_{1}^{*}}+\frac{r_{2} P_{2}}{n_{2} V_{g} Q_{2}^{*}}
\end{aligned}
$$

where $Q_{1}^{*}$ and $Q_{2}^{*}$ are rated reactive powers of the 1 st and 2 nd DG , respectively. With taking the ratio $k_{Q}=Q_{1}^{*}: Q_{2}^{*}$, Equation (29) is rewritten as: 


$$
\Delta Q=Q_{2}^{*}[\underbrace{\frac{\left(V^{*}-V_{g}\right)\left(n_{2}-k_{Q} n_{1}\right)}{k_{Q} n_{1} n_{2}}}_{\text {First error term }}+\underbrace{\frac{k_{Q} n_{1} r_{2} P_{2}-n_{2} r_{1} P_{1}}{k_{Q} n_{1} n_{2} V_{g}}}_{\text {Second error term }}]
$$

Equation (30) shows that the error of reactive power sharing includes two terms. The first error term depends on the operation voltage of common bus $V_{g}$ and the relationship between two $Q-V$ droop gains. The second error term is mainly determined by the mismatch line resistance $r$ and output active power $P$, simultaneously.

Firstly, to reduce the first error term, we choose the values of $n_{1}$ and $n_{2}$ as follows:

$$
n_{2}=k_{Q} n_{1}
$$

Secondly, in steady state, the output active power of DGs satisfies the following relationships [13].

$$
\frac{P_{1}}{P_{2}}=\frac{P_{1}^{*}}{P_{2}^{*}}=\frac{m_{2}}{m_{1}}
$$

where $P_{1}^{*}$ and $P_{2}^{*}$ are rated active powers of the 1st and 2nd DG , respectively. With taking the ratio $k_{P}=P_{1}^{*}: P_{2}^{*}$, Equation (30) is rewritten by substituting Equation (31) into Equation (30).

$$
\Delta Q=\frac{r_{2}-r_{1} k_{P}}{k_{Q} n_{1} V_{g}} P_{2} Q_{2}^{*}
$$

From Equation (33), the total error of reactive power sharing would be approximately decreased to zero when meeting the special condition in Equation (34).

$$
k_{P}=\frac{P_{1}^{*}}{P_{2}^{*}}=\frac{r_{2}}{r_{1}}
$$

However, the line resistance is normally constant after DG unit installation, and its value does not match each other in Equation (34). From Equation (29), same values of virtual resistance is not helpful to improve the reactive power sharing for two DGs. Thus, it is necessary to shape desired output impedances by eliminating the mismatch line resistance [16]. As the line resistances can be calculated or measured according to the actual line material and length in low-voltage AC microgrid, the virtual resistance is designed as shown in Equation (35) and Figure 4.

$$
r_{v i}=r_{r e f_{-} i}-r_{i}
$$

where $r_{v i}$ and $r_{i}$ are the values of virtual resistance and line resistance, respectively. $r_{\text {ref } \_-i}$ is the reference value of compensation (hereafter referred to as reference resistance), which should be chosen according to Equation (34).

$$
\frac{r_{r e f \_2}}{r_{r e f \_1}}=\frac{P_{1}^{*}}{P_{2}^{*}}
$$

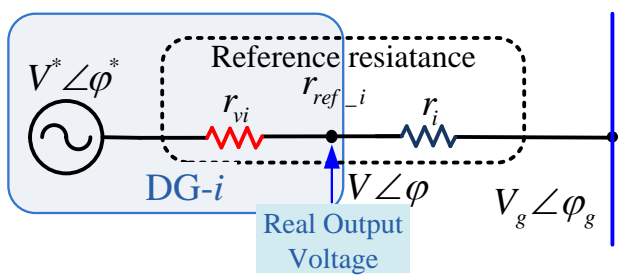

Figure 4. Equivalent output voltage source considering virtual resistance. 
In Figure 4, once the virtual resistance takes effect, the equivalent reference resistance of DG units will become matched to each other as in Equation (36). Due to the compatible operation, the reactive power is shared proportionally among DGs.

This study presents a simple method in Equations (31), (35) and (36) to guarantee accurate reactive power sharing based on the known line resistance. There are also some other measures to improve the reactive power sharing, such as adaptive voltage droop control [34,35], synchronized reactive power compensation [36], $Q-\dot{V}$ droop control [37], droop control based synchronized operation [38], virtual impedance method [39,40], and hierarchical droop control [41]. Then, the methods in [34-41] can also be extended to the resistive lines of low voltage microgrid.

\section{Guide on Designing the $Q-V$ Droop Gains Considering Stability, Reactive Output Capacity, and Reactive Power Sharing}

From above analysis, the values of the $Q-V$ droop gains are vital from the perspective of stability, reactive output capacity, and reactive power sharing. According to Equation (2), in steady state, $n$ should meet the following equation in order to guarantee the voltage quality.

$$
n<\frac{V_{\max }-V_{\min }}{Q_{\max }}
$$

where $Q_{\max }$ represents the maximum reactive power; and $V_{\max }$ and $V_{\min }$ are the maximum and minimum allowable microgrid voltage magnitude, respectively.

Considering both the stability aspect in Equation (17) and reactive output capacity in Equation (37), the synthesized range of $n$ is obtained.

$$
\frac{r}{2 \sqrt{3} V^{0}-2 V_{g}^{0}}<n<\min \left\{\frac{V_{\max }-V_{\min }}{Q_{\max }}, \frac{2 r}{V_{g}^{0}}\right\}
$$

Furthermore, from Equation (29), the bigger the value of $n$ is, the higher the accuracy of reactive power sharing becomes. Thus, the value of $n$ should be designed as large as possible in Equation (38).

On the other hand, if $n$ is chosen only considering the stability aspect and reactive power sharing $\left(n=2 r / V_{g}^{0}\right)$, the maximum reactive power is also obtained according to Equation (37):

$$
Q_{\max }<\frac{V_{g}^{0}\left(V_{\max }-V_{\min }\right)}{2 r}
$$

To test the robustness of the predefined $n$, the stability is analyzed while varying the line resistance, the load active power, and load reactive power. Taking the parameters of DG1 in Case A of Section 6 as an example, the dominant pole of Equation (13) is shown in Figure 5, and some conclusions are summarized as follows:

(1) For different line resistances in Figure 5a, the system is always stable during $r \in[0.1,3.4)$. When the line resistance is too large, $n$ should be redesigned according to Equation (38);

(2) Figure $5 \mathrm{~b}$ reveals that the output active power has little effect on the system stability;

(3) Figure $5 c$ reveals that $n$ is always applicable in a larger range of output reactive power.

In short, the predefined $Q-V$ droop gain is robust subject to the varying line resistance, the load power. 

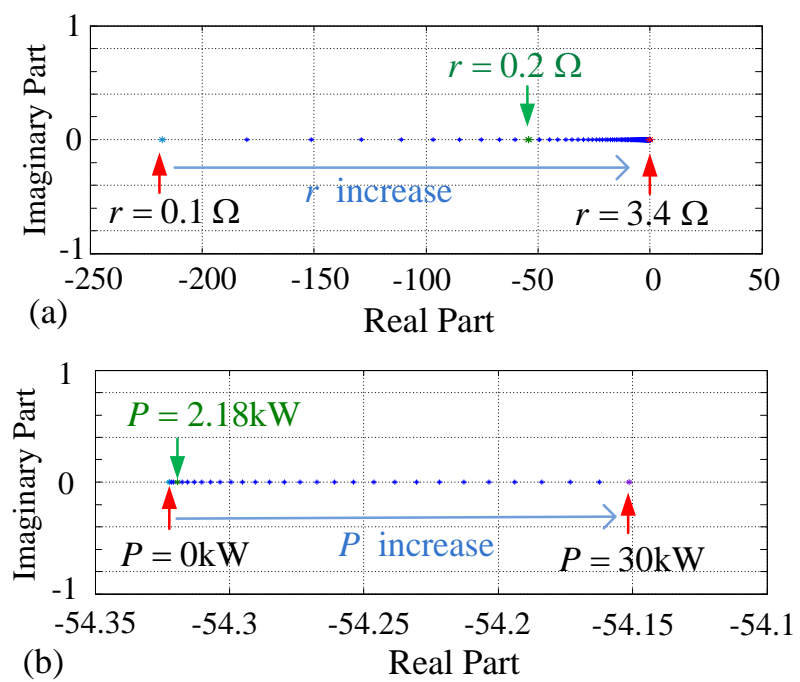

(b)

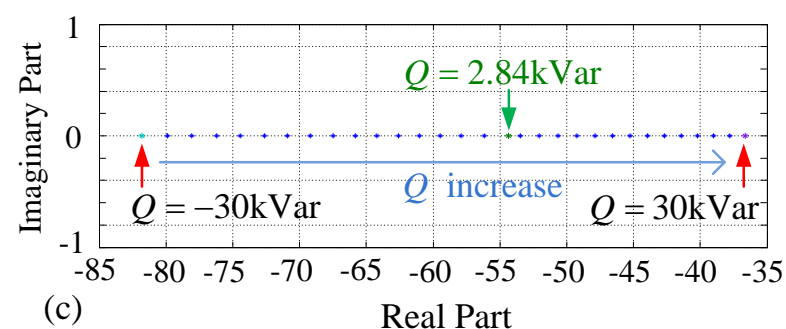

Figure 5. Dominant pole of Equation (13) for different conditions: (a) different line resistances; (b) different load active power; and (c) different load reactive power.

\section{Simulation Results}

To investigate the validity of conventional $P-\omega / Q-V$ droop control in highly resistance line, a single-phase converter-based AC microgrid with two DGs is built. The referent voltage frequency $f^{*}$ and amplitude $V^{*}$ are $50 \mathrm{~Hz}$ and $330 \mathrm{~V}$, respectively. The other simulation parameters are shown in Table 2.

Table 2. Simulation Parameters of Six Cases.

\begin{tabular}{|c|c|c|c|c|c|c|c|c|c|c|}
\hline \multirow[t]{2}{*}{ Cases } & \multicolumn{2}{|c|}{$\begin{array}{c}P \text { - } \omega \text { Droop Gain } \\
m(\mathrm{rad} / \mathrm{W} \cdot \mathrm{s})\end{array}$} & \multicolumn{2}{|c|}{$\begin{array}{c}Q-V \text { Droop } \\
\text { Gain } n \text { (V/Var) }\end{array}$} & \multicolumn{2}{|c|}{$\begin{array}{c}\text { Virtual } \\
\text { Resistance }(\Omega)\end{array}$} & \multicolumn{2}{|c|}{ Line Characters $(\Omega)$} & \multicolumn{2}{|c|}{ Load Characters $(\Omega)$} \\
\hline & $\begin{array}{c}\text { DG1 } \\
\left(10^{-5}\right)\end{array}$ & $\begin{array}{c}\text { DG2 } \\
\left(10^{-5}\right)\end{array}$ & $\begin{array}{c}\text { DG1 } \\
\left(10^{-3}\right)\end{array}$ & $\begin{array}{l}\text { DG2 } \\
\left(10^{-3}\right)\end{array}$ & DG1 & DG2 & DG1 & DG2 & $\begin{array}{l}0-0.7 \mathrm{~s}, \\
1.4-2 \mathrm{~s}\end{array}$ & $0.7-1.4 \mathrm{~s}$ \\
\hline Case A & 6.28 & 6.28 & 1 & 1 & 0 & 0 & 0.2 & 0.3 & $6+j 6$ & $4+j 4$ \\
\hline Case B & 6.28 & 6.28 & 1 & 1 & 0.1 & 0 & 0.2 & 0.3 & $6+j 6$ & $4+j 4$ \\
\hline Case C & 6.28 & 15.6 & 1 & 2 & 0 & 0.1 & 0.2 & 0.3 & $6+j 6$ & $4+j 4$ \\
\hline Case D & 6.28 & 6.28 & 1 & 1 & 0 & 0 & 0.2 & 0.3 & $6-j 6$ & $4-j 4$ \\
\hline Case E & 6.28 & 6.28 & 1 & 1 & 0.1 & 0 & 0.2 & 0.3 & $6-j 6$ & $4-j 4$ \\
\hline Case F & 6.28 & 6.28 & 1 & 1 & 0.13 & 0 & $\begin{array}{l}0.2568+ \\
j 0.0332\end{array}$ & $\begin{array}{l}0.3852+ \\
j 0.0498\end{array}$ & $6+j 6$ & $4+j 4$ \\
\hline
\end{tabular}

\subsection{Case A: Two DGs with Same Power Rating under Resistance-Inductance Load}

In this case, the droop gains $m=6.28 \times 10^{-5} \mathrm{rad} / \mathrm{w} \cdot \mathrm{s}$ and $n=1 \times 10^{-3} \mathrm{~V} /$ Var are selected for two DGs according to Equation (38). The detailed parameters of lines and load are available in Figure 6. During $0-0.7 \mathrm{~s}$, the microgrid operates in the state of Figure 6a. To study the dynamic response, the load power changes at $t=0.7 \mathrm{~s}$, and the operation state is switched to that as shown in Figure $6 \mathrm{~b}$. 
During 1.4-2 s, the state is recovered to that in Figure 6a. Figure 7 shows the real waveforms of power, voltage, current, and power angle.

From the simulation results in Figures 6 and 7, the conventional droop control can function well in pure resistive line of $\mathrm{AC}$ microgrid. Figure 7a shows that the active power is equally shared by two DGs. Figure 7b shows that the DG1 with smaller line resistance injects greater reactive power to inductive loads than DG2. Thus, the virtual resistance should be adopted to shape the desired output resistance.
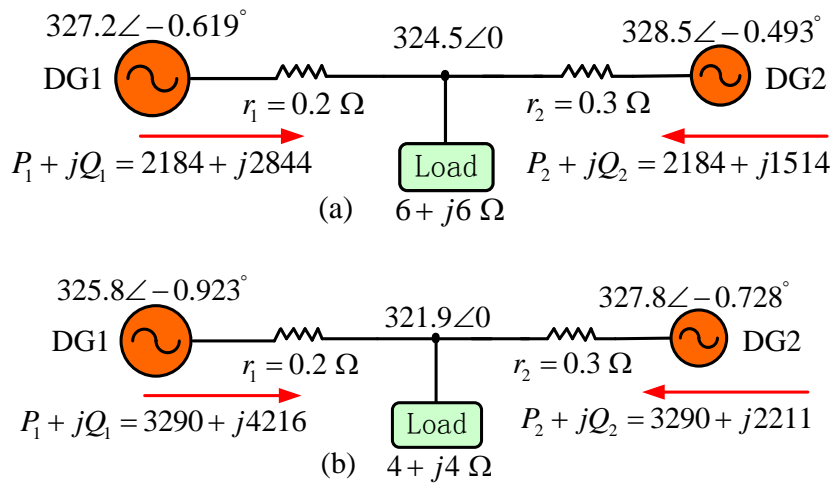

Figure 6. Simulation parameters and results in Case A: (a) during 0-0.7 s and 1.4-2 s; and (b) during $0.7-1.4 \mathrm{~s}$.
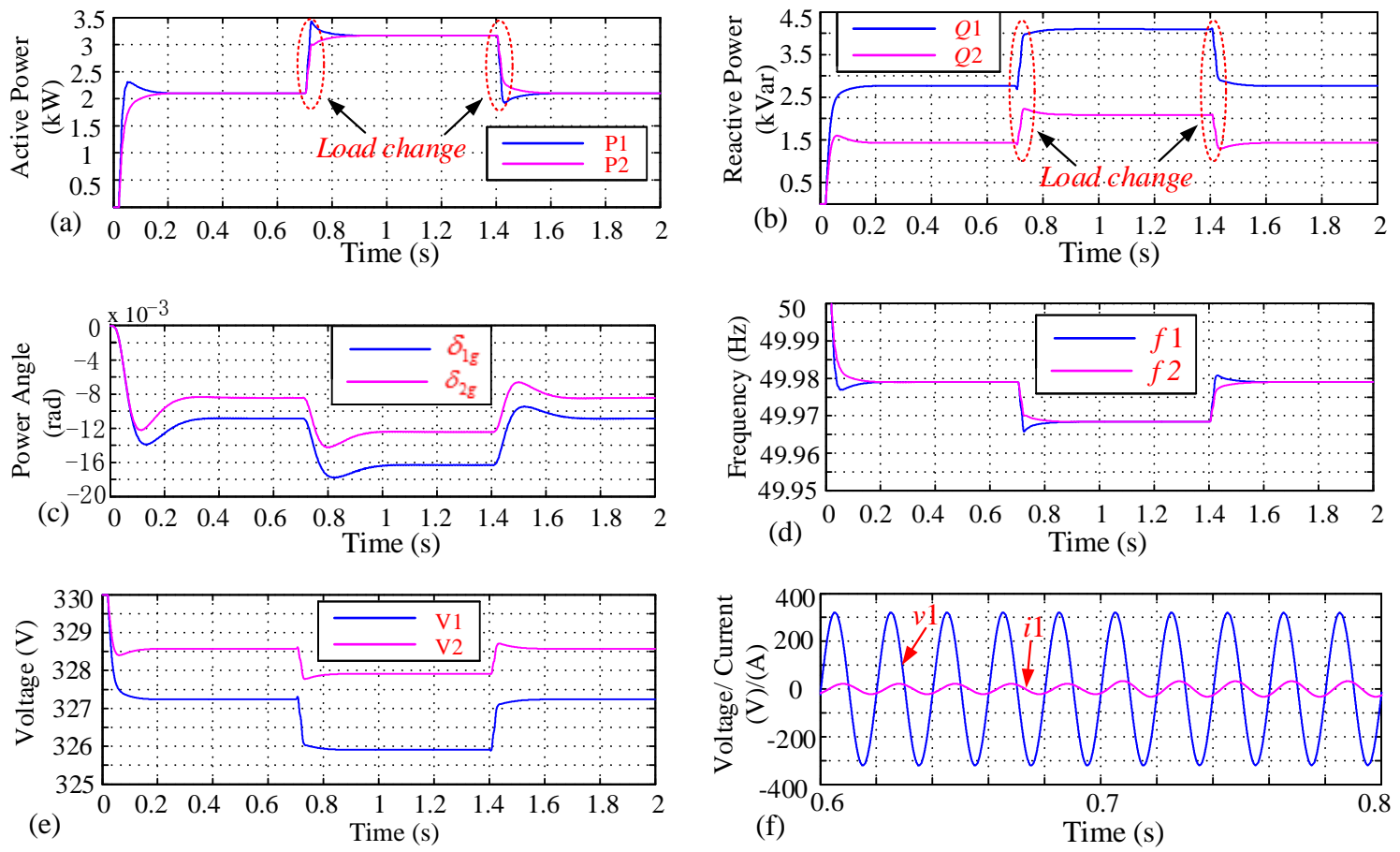

Figure 7. Simulation results in Case A: (a) active power; (b) reactive power; (c) power angle; (d) frequency; (e) voltage amplitude; and (f) voltage and current of DG1.

\subsection{Case B: Virtual Resistance of DG1 to Improve Reactive Power Sharing under Resistance-Inductance Load}

Compared with the simulation parameters of Case A, only virtual resistance $r_{v 1}=0.1 \Omega$ of DG1 is added according to Equations (35) and (36). Simulation results are shown in Figure 8. Compared with Figure $7 \mathrm{~b}$, the reactive power sharing difference between two DGs is greatly reduced, which verifies the effectiveness of virtual resistance. 

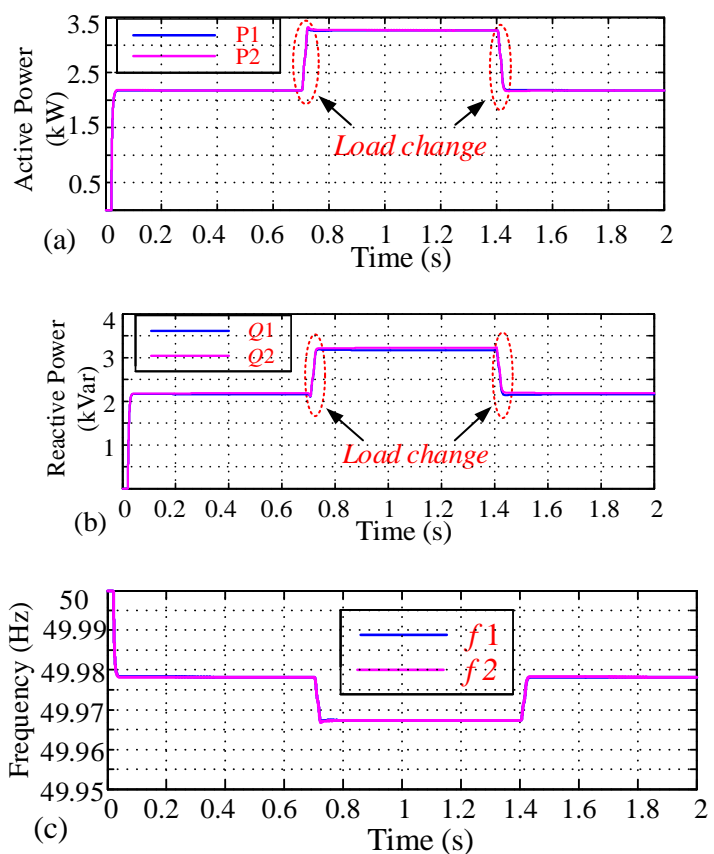

Figure 8. Simulation results in Case B: (a) active power; (b) reactive power; and (c) frequency.

\subsection{Case C: Both Power Rating of DG1 Are Twice Those of DG2 under Resistance-Inductance Load}

In this case, to verify the proportionate power sharing of both DGs, the $P$ - $\omega$ droop gain $m$ and $Q-V$ droop gain $n$ are chose according to Equations (31) and (32) as shown in Table 2.

$$
m_{2}=2 m_{1} ; \quad n_{2}=2 n_{1}
$$

Moreover, to guarantee the accurate reactive power sharing, virtual resistance $r_{v 2}$ of DG2 is added according to Equations (35) and (36).

$$
\begin{aligned}
& r_{r e f \_2}=2 r_{r e f_{-} 1}=0.4 \Omega \\
& r_{v 2}=r_{r e f_{\_} 2}-r_{2}=0.1 \Omega
\end{aligned}
$$

Simulation results are shown in Figure 9. It reveals that output active and reactive powers of DG1 are exactly twice those of DG2.
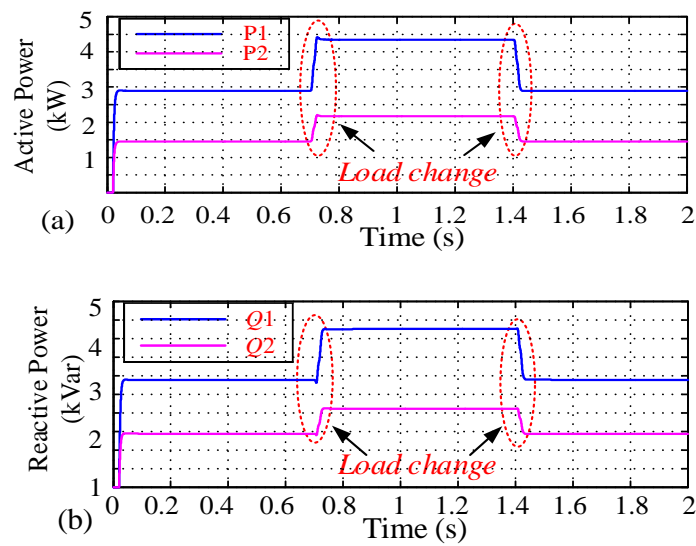

Figure 9. Cont. 


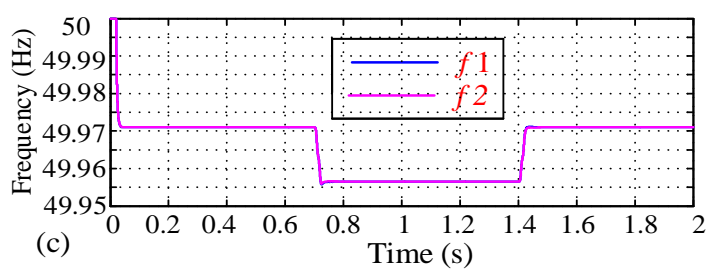

Figure 9. Simulation results in Case C: (a) active power; (b) reactive power; and (c) frequency.

\subsection{Case D: Two DGs with the Same Power Rating under Resistance-Capacitance Load}

Compared with the simulation parameters of Case A, only inductive loads are changed to capacitive loads. Simulation results are shown in Figures 10 and 11. Equation (38) is also workable according to the values of control parameters and operation point.

Figure $11 \mathrm{~b}$ reveals that there is an error of reactive power sharing among two DGs. Thus, it is necessary to take the measure of virtual resistance method.
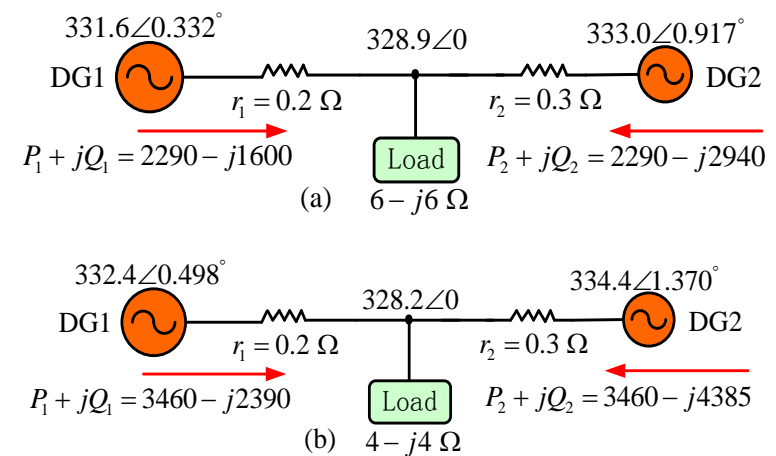

Figure 10. Simulation parameters and results in Case D: (a) during 0-0.7 s and 1.4-2 s; and (b) during $0.7-1.4 \mathrm{~s}$.
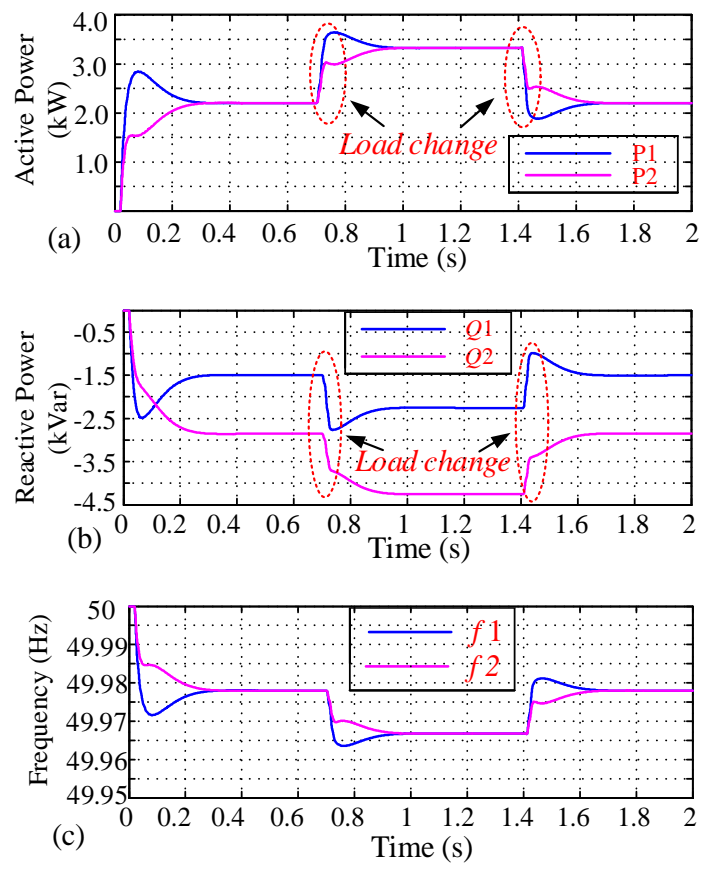

Figure 11. Simulation results in Case D: (a) active power; (b) reactive power; and (c) frequency. 
6.5. Case E: Virtual Resistance of DG1 to Improve Reactive Power Sharing under Resistance-Capacitance Load

Similar to the virtual resistance method of Case $B$, virtual resistance $r_{v 1}=0.1 \Omega$ of DG1 is added according to Equations (35) and (36). Simulation results are shown in Figure 12. Compared with Figure $11 b$, the reactive power sharing difference between two DGs is greatly reduced, which verifies the effectiveness of virtual resistance under RC loads.
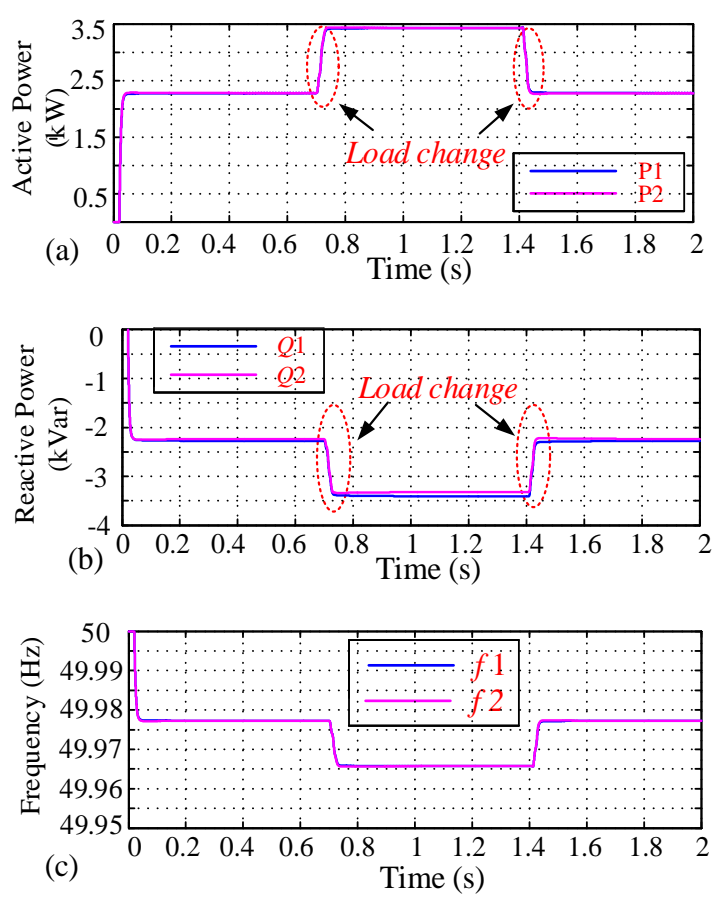

Figure 12. Simulation results in Case E: (a) active power; (b) reactive power; and (c) frequency.

\subsection{Case F: Validity of Conventional Droop Control in Highly Resistive Line of AC Microgrid}

In this case, the validity of conventional droop control is tested in the line parameters of low-voltage AC microgrid as presented in Table 1. The line lengths of DG1 and DG2 are $400 \mathrm{~m}$ and $600 \mathrm{~m}$, respectively. From the simulation results in Figures 13 and 14, the conventional droop control is quite applicable for the highly resistive line of AC microgrid.

As the line character is mainly resistive $(R>>X)$ in low voltage microgrid, the above analysis and simulations are reasonable by neglecting the minor line reactance and treating the highly resistive line as pure resistance.

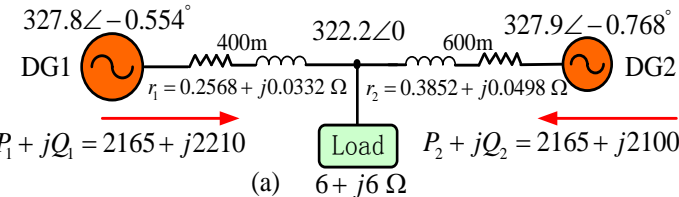

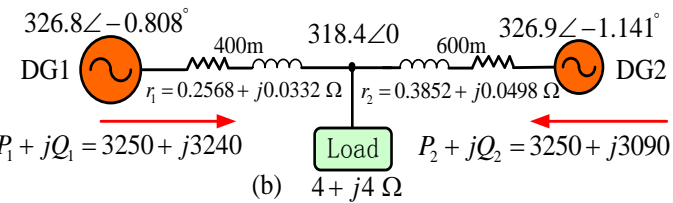

Figure 13. Simulation parameters and results in Case F: (a) during 0-0.7 s and 1.4-2 s; and (b) during $0.7-1.4 \mathrm{~s}$. 

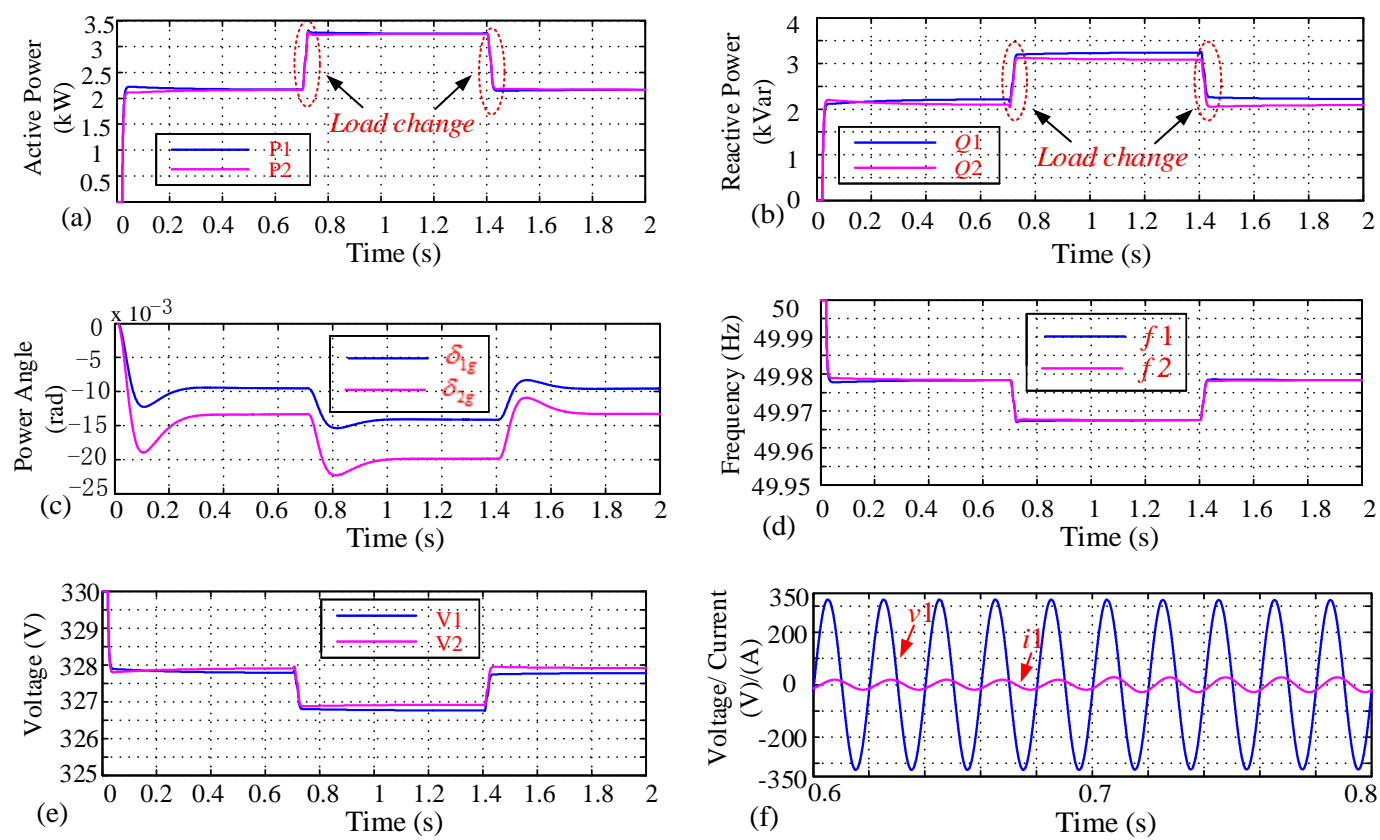

Figure 14. Simulation results in Case F: (a) active power; (b) reactive power; (c) power angle; (d) frequency; (e) voltage amplitude; and (f) voltage and current of DG1.

\section{Experiment Results}

A converter-based microgrid prototype is built in lab as shown in Figure 15. The microgrid consists of two micro-sources based on single-phase inverter. The main circuits are shown in Figure 16, which includes the experiment parameters for output filter, line, and load. The sample frequency is $12.8 \mathrm{kHz}$. The referent voltage frequency $f^{*}$ and amplitude $V^{*}$ are $50 \mathrm{~Hz}$ and $48 \mathrm{~V}$, respectively.

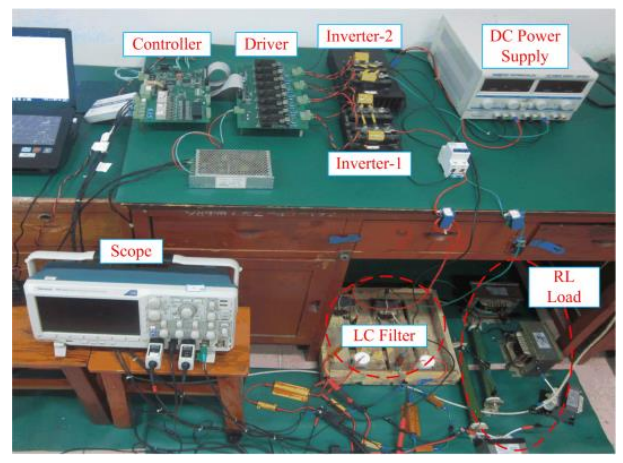

Figure 15. Prototype of parallel inverters system setup.

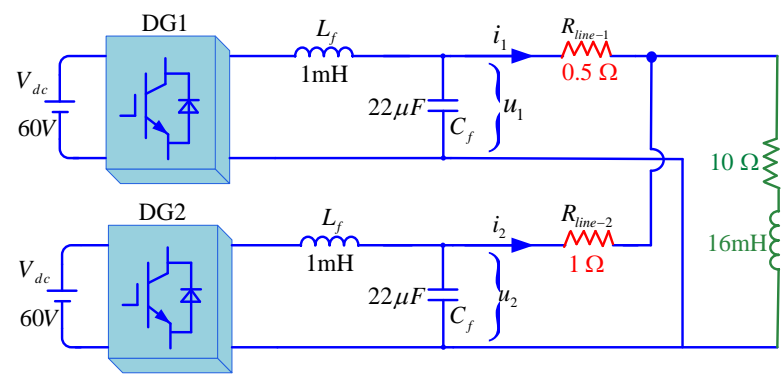

Figure 16. Main circuits of the experiment system. 


\subsection{Case I: Two DGs with the Same Power Rating}

According to Equation (38), the droop gains $m=3.14 \times 10^{-3} \mathrm{rad} / \mathrm{W} \cdot \mathrm{s}$ and $n=2 \times 10^{-2} \mathrm{~V} /$ Var are selected for two DGs. Figure 17 shows the measured waveforms with the conventional droop control methods. The waveforms from top to down are the output voltage $\left(\boldsymbol{U}_{1}\right)$ of inverter 1 , the output current $\left(\boldsymbol{I}_{\mathbf{1}}\right)$ of inverter 1 , the output voltage $\left(\boldsymbol{U}_{\mathbf{2}}\right)$ of inverter 2 and the output current $\left(\boldsymbol{I}_{2}\right)$ of inverter 2 . The voltage amplitudes of inverter 1 and 2 are $45.7 \mathrm{~V}$ and $46.4 \mathrm{~V}$, respectively. The current amplitudes of inverter 1 and 2 are $2.16 \mathrm{~A}$ and $1.65 \mathrm{~A}$, respectively.

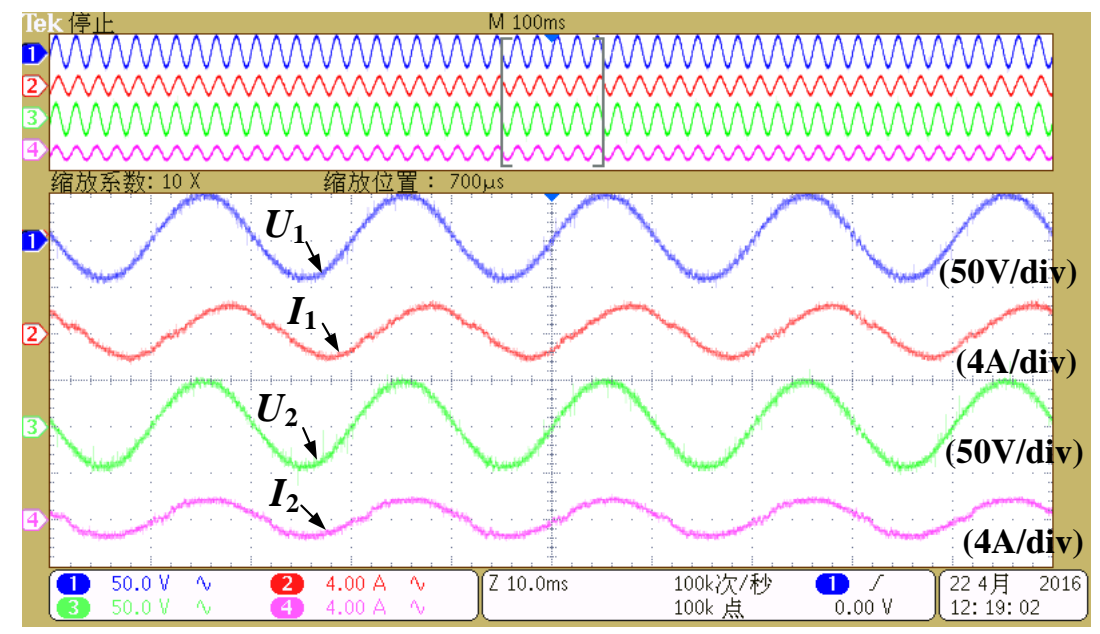

Figure 17. Steady state experimental waveforms of Case I.

Figure 18 shows the steady-state output active and reactive power of each inverter with the conventional droop control. The steady-state output active powers of the inverters are $36.6 \mathrm{~W}$ and $36.5 \mathrm{~W}$, and the output reactive powers are 36.1 Var and 9.1 Var. When using conventional $P$ - $\omega$ droop control, no active power divergence appear since frequency is a global variable, i.e. same frequency can be measured along the microgrid; however, voltage may drop along the microgrid power lines, which produces the well know reactive power divergence.
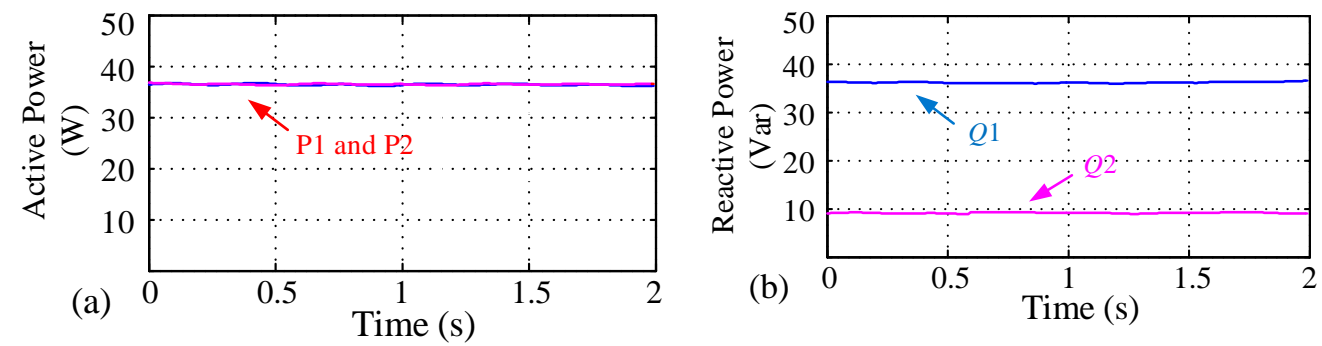

Figure 18. Steady-state power of Case I: (a) active power; and (b) reactive power.

\subsection{Case II: The Active Power Rating of DG1 Is Twice that for DG2}

To investigate the proper active power sharing, the $P-\omega$ droop gain of DG1 is changed to $m=1.57 \times 10^{-3} \mathrm{rad} / \mathrm{W} \cdot \mathrm{s}$ compared with the experiment parameters of Case I. Figures 19 and 20 show the measured waveforms and output power with the conventional droop control methods, respectively.

The voltage amplitudes of inverter 1 and 2 are $46.1 \mathrm{~V}$ and $46.0 \mathrm{~V}$, respectively. The current amplitudes of inverter 1 and 2 are $2.12 \mathrm{~A}$ and $1.78 \mathrm{~A}$, respectively. The steady-state output active powers of the inverters are $48.9 \mathrm{~W}$ and $24.7 \mathrm{~W}$, and the output reactive powers are 12.16 Var and 33.34 Var. Figure 20 reveals that output active power of DG1 is twice that for DG2. 


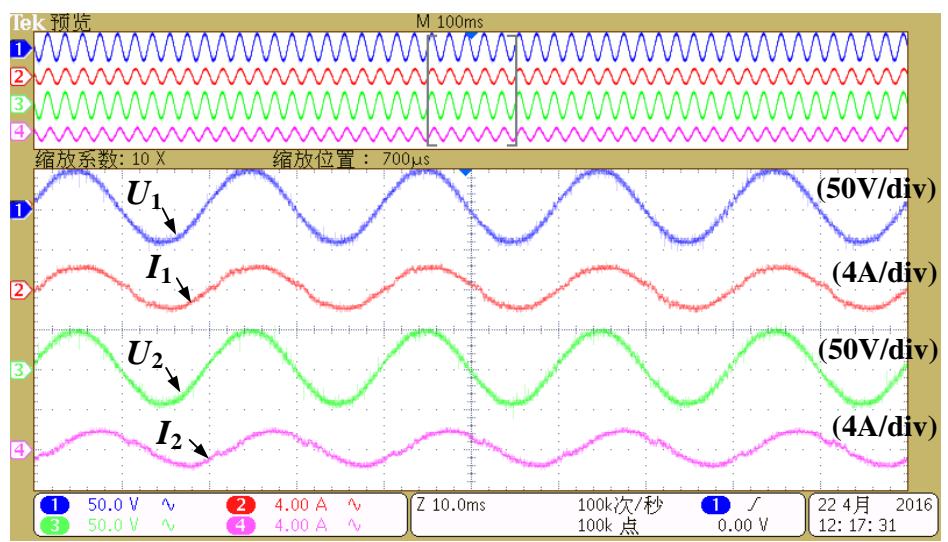

Figure 19. Steady state experimental waveforms of Case II.
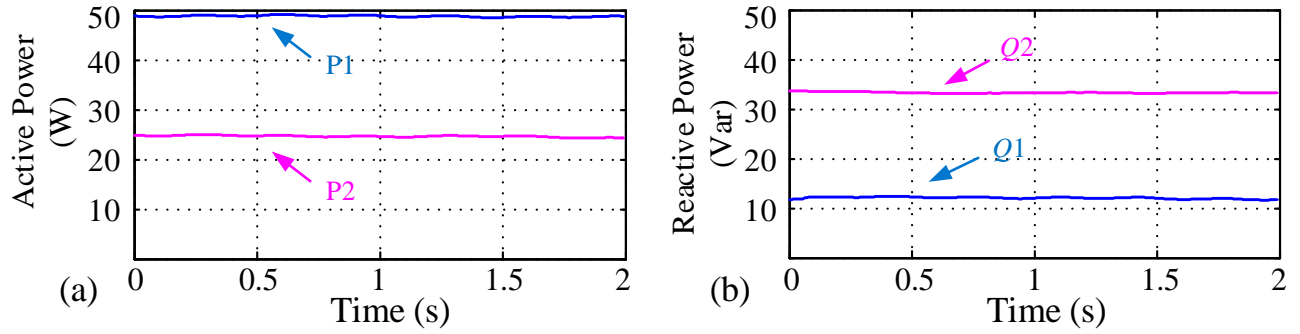

Figure 20. Steady-state power of Case II: (a) active power; and (b) reactive power.

\subsection{Case III: Redesign the Q-V Droop Gains of DG1 to Improve the Reactive Power Sharing}

To improve the reactive power sharing, the virtual resistance $r_{v 1}=0.5 \Omega$ of DG1 is adopted according to Equations (35) and (36) compared with the experiment parameters of Case I.

Figures 21 and 22 show the measured waveforms and output power with the conventional droop control methods, respectively. The voltage amplitudes of inverter 1 and 2 are $45.7 \mathrm{~V}$ and $46.1 \mathrm{~V}$, respectively. The current amplitudes of inverter 1 and 2 are $1.82 \mathrm{~A}$ and $1.80 \mathrm{~A}$, respectively. The steady-state output active powers of the inverters are $36.3 \mathrm{~W}$ and $36.0 \mathrm{~W}$, and the output reactive powers are 23.9 Var and 21.9 Var. The minor error of reactive power sharing might be caused by the line resistance error. These results indicate that the virtual resistance method has no effect on the active power sharing performance, but makes reactive power be shared roughly.

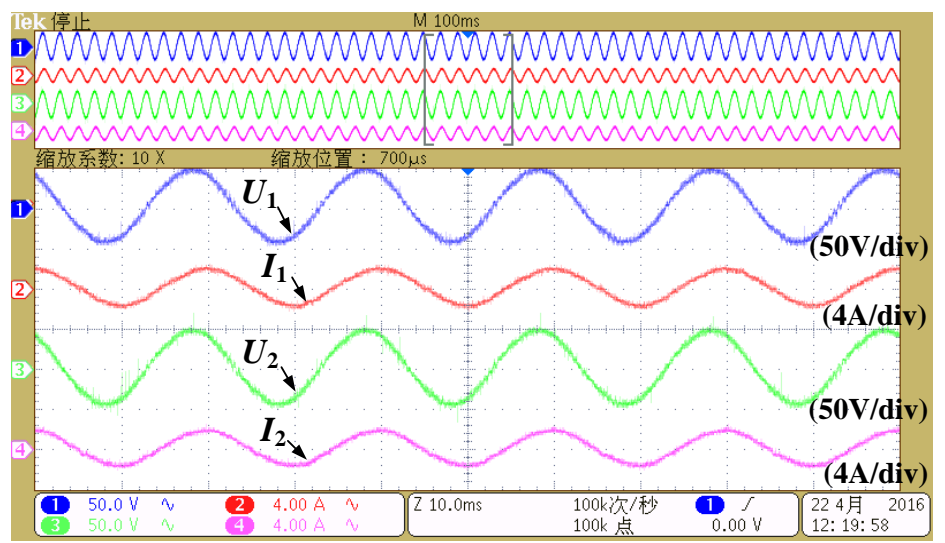

Figure 21. Steady state experimental waveforms of Case III. 

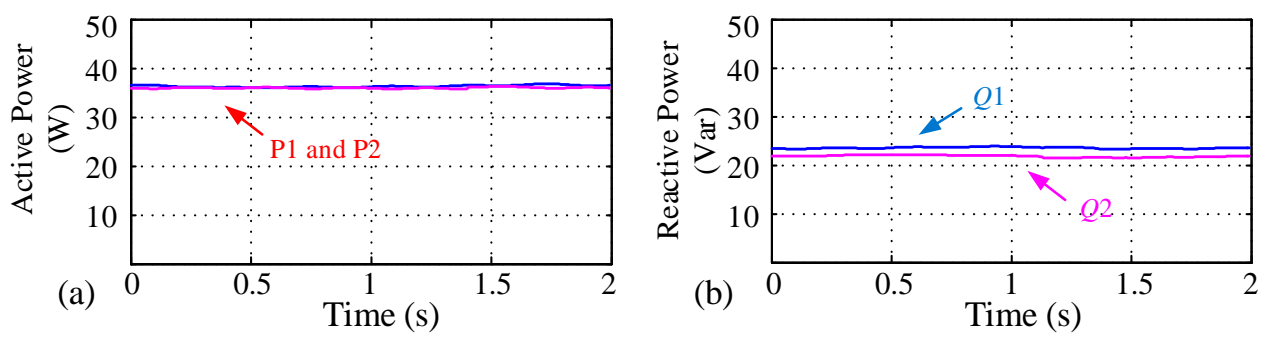

Figure 22. Steady-state power of Case III: (a) active power, and (b) reactive power.

\section{Conclusions}

This paper presents that the conventional droop control is still valid in highly resistive line of low-voltage AC microgrid. Small signal analysis is constructed to verify the effectiveness. A detail explanation is also given to help researcher understand the explicit reason. As the $Q-V$ droop gain $n$ is vital from the perspective of stability, reactive output capacity, and reactive power sharing, the design guides of $Q-V$ droop gain are given. Simulation and experiment results reveal that the power sharing and transient process are satisfactory. Moreover, the conventional droop control can be regarded as a universal control of parallel-connected DGs with different line impedances, which is the future work of this study.

Furthermore, as the expansion of main ideas in this study, the VPD/FQB method can also be applied in highly inductive line of AC microgrid. Thus, the reactive power sharing among the DGs could be obtained easily. In pure inductive line, the VPD/FQB method and the physical transmission equations are presented as:

$$
\begin{gathered}
\left\{\begin{array}{c}
V=V^{*}-n P \\
\omega=\omega^{*}+m Q
\end{array}\right. \\
\left\{\begin{array}{l}
P=\frac{V V_{g}}{X} \sin \delta \\
Q=\frac{V\left(V-V_{g} \cos \delta\right)}{X}
\end{array}\right.
\end{gathered}
$$

Similar to Figure 3, the whole small signal model of Equations (43) and (44) are shown in Figure 23.

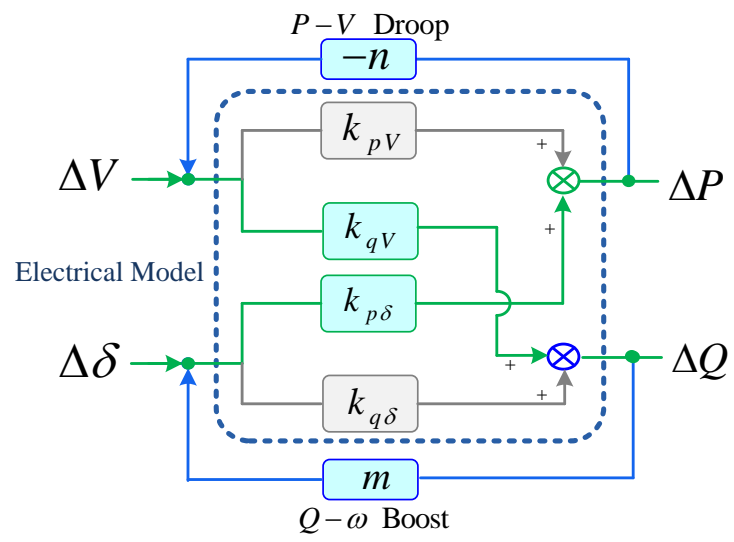

Figure 23. The whole small signal model in pure inductive line of AC microgrid.

Acknowledgments: This work was supported by the National Natural Science Foundation of China under Grants 61573384 and 61622311, the Natural Science Foundation of Hunan Province of China under Grant No. 2016JJ1019, the Project of Innovation-driven Plan in Central South University, and the Fundamental Research Funds for the Central Universities of Central South University under Grant 2016zzts347. 
Author Contributions: Xiaochao Hou conceived the main idea and wrote the manuscript with guidance from Yao Sun and Hua Han. Wenbin Yuan and Chaolu Zhong performed the experiments; and Josep M. Guerrero reviewed the work and gave helpful improvement suggestions.

Conflicts of Interest: The authors declare no conflict of interest.

\section{References}

1. Lasseter, R.H.; Paigi, P. Microgrid: A conceptual solution. In Proceedings of the 2004 IEEE Power Electro Special Conference, Aachen, Germany, 20-25 June 2004; pp. 4285-4290.

2. Yan, B.; Wang, B.; Zhu, L. A novel, stable, and economic power sharing scheme for an autonomous microgrid in the energy internet. Energies 2015, 8, 12741-12764. [CrossRef]

3. Ahn, C.; Peng, H. Decentralized and real-time power dispatch control for an islanded microgrid supported by distributed power sources. Energies 2013, 6, 6439-6454. [CrossRef]

4. Golsorkhi, M.S.; Lu, D.D.C. A control method for inverter-based islanded microgrids based on V-I droop characteristics. IEEE Trans. Power Deliv. 2015, 30, 1196-1204. [CrossRef]

5. Pogaku, N.; Prodanovic, M.; Green, T.C. Modeling, analysis and testing of autonomous operation of an inverter-based microgrid. IEEE Trans. Power Electron. 2007, 22, 613-625. [CrossRef]

6. He, J.W.; Li, Y.; Bosnjak, D.; Harris, B. Investigation and active damping of multiple resonances in a parallel-inverter-based microgrid. IEEE Trans. Power Electron. 2013, 28, 234-246. [CrossRef]

7. Abdelaziz, M.M.A.; Shaaban, M.F.; Farag, H.E.; El-Saadany, E.F. A multistage centralized control scheme for islanded microgrids with PEV. IEEE Trans Sustain. Energy 2014, 5, 927-937. [CrossRef]

8. Song, N.O.; Lee, J.H.; Kim, H.M.; Im, Y.H.; Lee, J.Y. Optimal energy management of multi-microgrids with sequentially coordinated operations. Energies 2015, 8, 8371-8390. [CrossRef]

9. Caldognetto, T.; Paolo, T. Microgrids operation based on master-slave cooperative control. IEEE J. Emerg. Sel. Top. Power Electron. 2014, 2, 1081-1088. [CrossRef]

10. Sun, Y.; Zhong, C.; Hou, X.; Yang, J.; Han, H.; Guerrero, J.M. Distributed cooperative synchronization strategy for multi-bus microgrids. Int. J. Electr. Power Energy Syst. 2017, 86, 18-28. [CrossRef]

11. Lim, Y.; Kim, H.M.; Kinoshita, T. Distributed load-shedding system for agent-based autonomous microgrid operations. Energies 2014, 7, 385-401. [CrossRef]

12. Yu, Z.; Ai, Q.; Gong, J.; Piao, L. A novel secondary control for microgrid based on synergetic control of multi-agent system. Energies 2016, 9. [CrossRef]

13. Chandorkar, M.C.; Divan, D.M.; Adapa, R. Control of parallel connected inverters in standalone AC supply systems. IEEE Trans. Ind. Appl. 1993, 29, 136-143. [CrossRef]

14. Yu, X.; Khambadkone, A.M.; Wang, H. Control of parallel-connected power converters for low-voltage microgrid-Part I: A hybrid control architecture. IEEE Trans. Power Electron. 2010, 25, 2962-2970. [CrossRef]

15. Tuladhar, A.; Jin, H.; Unger, T.; Mauch, K. Control of parallel inverters in distributed ac power systems with consideration of line impedance effect. IEEE Trans. Ind. Appl. 2000, 36, 131-138. [CrossRef]

16. Guerrero, J.M.; Matas, J.; de Vicuña, L.G. Decentralized control for parallel operation of distributed generation inverters using resistive output impedance. IEEE Trans. Ind. Electron. 2007, 54, 994-1004. [CrossRef]

17. Han, H.; Hou, X.; Yang, J.; Wu, J.; Su, M.; Guerrero, J.M. Review of power sharing control strategies for islanding operation of AC microgrids. IEEE Trans. Smart Grid 2016, 7, 200-215. [CrossRef]

18. Zhong, Q.-C. Robust droop controller for accurate proportional load sharing among inverters operated in parallel. IEEE Trans. Ind. Electron. 2013, 60, 1281-1290. [CrossRef]

19. Zhong, Q.-C.; Hornik, T. Control of Power Inverters in Renewable Energy and Smart Grid Integration; Wiley-IEEE Press: Hoboken, NJ, USA, 2013.

20. He, J.; Li, Y. Analysis, design, and implementation of virtual impedance for power electronics interfaced distributed generation. IEEE Trans. Ind. Appl. 2011, 47, 2525-2538. [CrossRef]

21. Guerrero, J.M.; Vicuna, L.G.D.; Matas, J.; Castilla, M.; Miret, J. Output impedance design of parallel-connected UPS inverters with wireless load-sharing control. IEEE Trans. Ind. Electron. 2005, 52, 1126-1135. [CrossRef]

22. Li, Y.W.; Kao, C.-N. An accurate power control strategy for power-electronics-interfaced distributed generation units operating in a low-voltage multibus microgrid. IEEE Trans. Power Electron. 2009, 24, 2977-2988. 
23. Guerrero, J.M.; Vasquez, J.C.; Matas, J.; de Vicuna, L.G.; Castilla, M. Hierarchical control of droop-controlled AC and DC microgrids-A general approach toward standardization. IEEE Trans. Ind. Electron. 2011, 58, 158-172. [CrossRef]

24. Parhizi, S.; Lotfi, H.; Khodaei, A.; Bahramirad, S. State of the art in research on microgrids: A review. IEEE Access 2015, 3, 890-925. [CrossRef]

25. Bevrani, H.; Shokoohi, S. An intelligent droop control for simultaneous voltage and frequency regulation in islanded microgrids. IEEE Trans. Smart Grid 2013, 4, 1505-1513. [CrossRef]

26. Majumder, R.; Ledwich, G.; Ghosh, A. Droop control of converter-interfaced microsources in rural distributed generation. IEEE Trans. Power Deliv. 2010, 25, 2768-2778. [CrossRef]

27. Majumder, R.; Chaudhuri, B.; Ghosh, A. Improvement of stability and load sharing in an autonomous microgrid using supplementary droop control loop. IEEE Trans. Power Syst. 2010, 25, 796-808. [CrossRef]

28. Heuck, K.; Dettmann, K.D.; Reuter, E. Elektrische Energieversorgung; Vieweg: Berlin, Germany, 1991. (In German)

29. Engler, A.; Soultanis, N. Droop control in LV-grids. In Proceedings of the 2005 International Conference on Future Power Systems, Amsterdam, The Netherlands, 16-18 November 2005.

30. Mohamed, Y.; El-Saadany, E.F. Adaptive decentralized droop controller to preserve power sharing stability of paralleled inverters in distributed generation microgrids. IEEE Trans. Power Electron. 2008, 23, 2806-2816. [CrossRef]

31. Sao, C.K.; Lehn, P.W. Autonomous load sharing of voltage source converters. IEEE Trans. Power Deliv. 2005, 20, 1009-1016. [CrossRef]

32. Shintai, T.; Miura, Y.; Ise, T. Oscillation damping of a distributed generator using a virtual synchronous generator. IEEE Trans. Power Deliv. 2014, 29, 668-676. [CrossRef]

33. Jan, M.; Janusz, W.B.; James, R.B. Power System Dynamics: Stability, and Control; Wiley: Chichester, UK, 2008.

34. Rokrok, E.; Golshan, M.E.H. Adaptive voltage droop scheme for voltage source converters in an islanded multi-bus microgrid. IET Gener. Transm. Distrib. 2010, 4, 562-578. [CrossRef]

35. Mahmood, H.; Michaelson, D.; Jiang, J. Reactive power sharing in islanded microgrids using adaptive voltage droop control. IEEE Trans. Smart Grid 2015, 6, 3052-3060. [CrossRef]

36. He, J.; Li, Y.W. An enhanced microgrid load demand sharing strategy. IEEE Trans. Power Electron. 2012, 27, 3984-3995. [CrossRef]

37. Lee, C.T.; Chu, C.C.; Cheng, P.T. A new droop control method for the autonomous operation of distributed energy resource interface converters. IEEE Trans. Power Electron. 2013, 28, 1980-1993. [CrossRef]

38. Han, H.; Liu, Y.; Sun, Y.; Su, M.; Guerrero, J.M. An improved droop control strategy for reactive power sharing in islanded microgrid. IEEE Trans. Power Electron. 2015, 30, 3133-3141. [CrossRef]

39. Zhu, Y.; Zhuo, F.; Wang, F.; Liu, B.; Gou, R.; Zhao, Y. A virtual impedance optimization method for reactive power sharing in networked microgrid. IEEE Trans. Power Electron. 2016, 31, 2890-2904. [CrossRef]

40. Mahmood, H.; Michaelson, D.; Jiang, J. Accurate reactive power sharing in an islanded microgrid using adaptive virtual impedances. IEEE Trans. Power Electron. 2015, 30, 1605-1617. [CrossRef]

41. Milczarek, A.; Malinowski, M.; Guerrero, J.M. Reactive power management in islanded microgrid-Proportional power sharing in hierarchical droop control. IEEE Trans. Smart Grid 2015, 6, 1631-1638. [CrossRef]

(C) 2016 by the authors; licensee MDPI, Basel, Switzerland. This article is an open access article distributed under the terms and conditions of the Creative Commons Attribution (CC-BY) license (http://creativecommons.org/licenses/by/4.0/). 